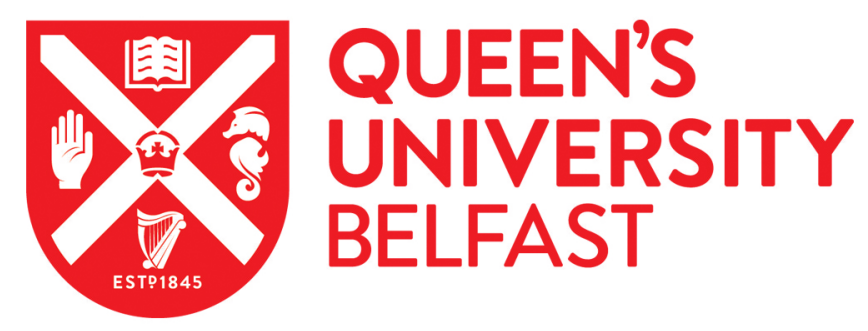

\title{
Meta-Theoretical Paradigms Underpinning Risk in Child Welfare: Towards a Position of Methodological Pragmatism
}

Houston, S. (2014). Meta-Theoretical Paradigms Underpinning Risk in Child Welfare: Towards a Position of Methodological Pragmatism. Children and Youth Services Review, 47(1), 55-60.

https://doi.org/10.1016/j.childyouth.2013.12.003

Published in:

Children and Youth Services Review

Document Version:

Peer reviewed version

Queen's University Belfast - Research Portal:

Link to publication record in Queen's University Belfast Research Portal

\begin{abstract}
Publisher rights
Copyright @ 2013 Elsevier Ltd. This is the author's version of a work that was accepted for publication in Children and Youth Services Review. Changes resulting from the publishing process, such as peer review, editing, corrections, structural formatting, and other quality control mechanisms may not be reflected in this document. Changes may have been made to this work since it was submitted for publication. A definitive version was subsequently published in Children and Youth Services Review, vol. 47, part 1, December 2014, doi: 10.1016/j.childyouth.2013.12.003.

\section{General rights}

Copyright for the publications made accessible via the Queen's University Belfast Research Portal is retained by the author(s) and / or other copyright owners and it is a condition of accessing these publications that users recognise and abide by the legal requirements associated with these rights.
\end{abstract}

\section{Take down policy}

The Research Portal is Queen's institutional repository that provides access to Queen's research output. Every effort has been made to ensure that content in the Research Portal does not infringe any person's rights, or applicable UK laws. If you discover content in the Research Portal that you believe breaches copyright or violates any law, please contact openaccess@qub.ac.uk. 


\section{Meta-Theoretical Paradigms Underpinning Risk in Child Welfare: Towards a Position of Methodological Pragmatism}

The aim of this paper is to explore the 'natural attitude' underpinning risk practices in child welfare. This refers to various taken-for-granted approaches to risk that social workers and other human service professionals draw upon in their everyday practice. The approach proceeds by identifying and critically examining three key, meta-theoretical paradigms on risk which typically shape the natural attitude. They are labelled 'objectivist, 'subjectivist' and 'critical'. The ontological, epistemological, axiological and methodological premises supporting each paradigm, and how they shape risk practices, are then reviewed leading to a composite, meta-theoretical position on risk termed 'methodological pragmatism'. This position draws on the strengths of each paradigm and is formulated into ten propositions which consider how risk should be approached in child welfare. Within this corpus of thought salient themes are endorsed such as the need for method triangulation, an examination of 'deep causality', and the promotion of emancipatory perspectives. By critically reflecting on meta-theory, the paper contributes to the development of substantive theories of risk assessment and management in child welfare.

Key words: Risk, child welfare, meta-theory, paradigms

\section{Introduction}

Risk continues to exercise the collective imagination in contemporary society. Whether the threat emanates from environmental disaster, economic melt-down, international terrorism, large scale epidemics or the vagaries of the lifecourse, our collective preoccupation with risk assessment, prediction and safety, still makes Ulrich Beck's (1992) watershed thesis on the 'risk society' apposite for today's world. This axiom takes on a particular purchase when we consider current discourses and approaches to risk in child welfare. In this context, risk has been medicalised, legalised and professionalised (Barsky, 2009; Lonne et al, 2009). We see these trends within various organisational contexts in social work, where an instrumental approach has been applied to the management of risk, often shoe-horning it into a framework of audit and governance - a trend that is counterinituitive, some argue (Kemshall, 2009; Broadhurst et al, 2010), given the inherently complex, contingent, negotiated, and multi-factorial nature of risk in social life.

Yet, despite these complexities, many social workers in child welfare engage in risk-led practice in a routinised way. Tellingly, one might opine that risk has become so dominant a lens it is now part of the profession's natural attitude, shaping the heuristics professionals use in a taken-for-granted way to make sense of complex situations. For some practitioners (depending on their location and setting), the natural attitude reflects a calculative stance, one that draws on actuarial principles; for others, the use of clinical judgement is the preferred modus operandi. This bifurcation has, at times, escalated into what White and 
Walsh (2006) refer to as the 'risk assessment wars'. Regardless of what stance is taken, though, and how it is critically interogated, a gap in the literature remains evident. This refers to the limited attention given to the meta-theories underpinning these various, takenfor-granted, risk practices in child welfare.

Meta-theory addresses questions of ontology (referring to our 'being' in the world), epistemology (related to ways of knowing) and axiology (concerning the nature of values). In this way, it deals with first-order philosophical premises about existence and the nature of society. Moreover, it lays the conceptual ground for the development of substantive theories in the social sciences (Sibeon, 2004). These are specific bodies of knowledge providing a more detailed understanding and explanation of different aspects of life such as, inter alia, human identity (Lawler, 2008) and the life course (Hunt, 2005). More broadly, a return to meta-theory enables the inquirer to understand, critique and improve substantive theory from the perspective of overarching views about social actors and social life.

The aim of this paper is, therefore, to define and consider the range of meta-theoretical premises on risk and how they shape the natural attitude supporting different risk practices with children facing various hazards in social life. In taking this step, I identify three overarching, meta-theoretical paradigms on risk and examine their ontological, epistemological, axiological and methodological suppositions. The strengths and weaknesses of each paradigm are then briefly appraised leading to an argument for a methodological pragmatism embracing an alignment of aspects of all three. Simply put, this suggests risk practices must be seen in the context of enabling and constraining psychosocial structures (which are often hidden from empirical register) and the impact of human agency. In this conception, risk practices are seen as the outcome of human intention and activity yet occur within the context of reproduced rules, norms and power, all of which circumscribe or limit creative action.

This exercise in philosophical and conceptual deliberation is much needed if we are to understand more fully contemporary risk in human welfare and how to respond to it with greater insight. Reflecting on meta-theory brings us back to fundamental assumptions which, if left uninspected, continue to mould actions in the empirical world. Our deepest beliefs, which are often implicitly held, influence what Giddens (1987) referred to as practical consciousness: how we act in an automatic way, 'doing things' instinctually rather than cogitating on them deliberately. Practical consciousness is like the beam of a torch lightening up only certain parts of a path while neglecting the wider terrain. Meta-theory illuminates this broader canvass of social life enabling us to challenge the wisdom of received ideas and long-held shibboleths.

This is an inquiry that moves from surface to depth, excavating unchallenged notions of risk lying behind the meniscus of everyday social work practice and therefore is congruent with a Socratic disposition which examines closely the prevailing order from a critical perspective. 
The aim, in all of this, is to enhance practices making them more sensitive to lived experience, more value-oriented (challenging oppressive mechanisms) and more informed about the nature of the social domains affecting outcomes in the lifecourse. Risk is such a contested, emotionally charged and agonised concept and, as such, needs to be deconstructed if we are to make meaningful headway towards more enlightened practices.

\section{Key Meta-Theoretical Paradigms on Risk}

I argue there are three prominent, meta-theoretical paradigms informing risk practices in child welfare and have labelled them 'objectivist', 'subjectivist' and 'critical' (see Table 1 below). In reaching this particular formulation I have drawn on and re-worked the seminal contributions from Burrell and Morgan (1979) and Chua (1986) on the nature of sociological paradigms. For these theorists, paradigmatic assumptions are mainly shaped by objectivist/positivist ontologies on the one hand, and subjectivist/interpretivist ontologies, on the other. Based on Dahrendorf's (1959) sociological theory, they also posit that fundamental questions about the nature of society are formative in shaping the sociological imagination. More specifically, they concentrate on whether society is fundamentally held together by consensual relations and social order, the classic Parsonian view (1937), or is more oriented towards conflictual relations, power, and coercion - as in the orthodox Marxian position. Endorsing the latter view of society, as conflict-bound, leads to a critical, emancipatory perspective.

\section{PLACE TABLE 1 HERE}

It is through a thematic analysis of these contributions that the three paradigms were developed. An important consideration in this exercise was to set out a typology which was relevant, conceptually speaking, to the nature of risk in social life but also germane to social work practice. In this regard, having a 'critical' paradigm was important in terms of social work's strident commitmment to anti-oppressive practice. Moreover, the categories of 'objectivism' and 'subjectivism' seemed appropriate for an examination of risk as they sourced different methodological approaches to risk assessment.

As can be seen from the table, each paradigm adopts a particular position on ontology, epistemology, axiology and methodology. Taking objectivism first, it propounds the ontological view that social phenomena exist independently of human agents. Here, social phenomena present as external facts which constrain or enable social action. Epistemologically, it suggests we can provide 'objective' representations of the social world in an accurate, valid and reliable manner. Reality can be discovered and communicated to others. Aligned to this supposition, it contends that knowledge claims are testable through empirical observation or experiment. From an axiological stance, by way of contrast, objectivism advances the view that scientific inquiry should be a neutral affair, one that is value-free and dispassionate. In discovering facts we cannot progress to moral assertions as 
they are two distinctive categories which must not be conflated. This is what proponents of the paradigm refer to as the inviolable, fact-value distinction.

Objectivism relies on modes of inquiry that are sourced by positivism. This doctrine asserts the only reliable knowledge is of the scientific kind. Positivism directs the inquirer to search for causal relationships and encourages the deductive testing of theory and hypotheses. It also leans towards a nomothetic orientation; that is, a search for general laws. That said, it is important to point out at this juncture that approaches to positivism have been tempered or even contested by various philosophers (for example, Popper (1968)) and social commentators (for instance, Benton and Craib (2001)). Thus, when it comes to contemporary sociological versions, the claimed neutrality of positivist methods has come under question particularly when it is conceded that observer bias may always be present in investigation even to a small degree. What is more, the sanctity of positivism's metaphysical premises has been overtaken by a focus on quantitative methods as the quintessential feature defining this approach. With this comes the pursuit of trustworthy data acquisition and analysis. Thus, positivism in modern social science is often seen as synonymous with applying scientific methods to study social phenomena without necessarily maintaining a rigid commitment to the approach's metaphysical claims concerning reality.

The afore-mentioned modes of inquiry give rise to the use of actuarial models in risk assessement in human welfare contexts. Such models, it is contended, enable the inquirer to reach an understanding of the level of seriousness of risk in a particular case rather than to predict specifically the occurrence of future harm (Shlonsky \& Wagner, 2005). Hence, they must be seen as risk classification tools. It is contended, by some, that actuarial models can rightly claim the mantle of the 'gold standard' of assessment approaches (Schwalbe, 2009). This is justified on the grounds they draw on positivist principles to identify risk factors which are statistically significant in reaching a considered formulation about dangerousness within families. Human subjectivity is curtailed as the respondant applies the model to score various categories thus minimising the distorting effects of unstructured, human judgement.

Subjectivism typically presents an antithetical view to the fore-going tenets. Thus, when it comes to the area of ontology, it proposes a model of voluntarism (Giddens, 1987) whereby individual actors are not 'cultural dopes' but rather exercise their intentions, hopes, choices and decisions. In effect, they exercise their freedom to change themselves and social structures. Two other dimensions of subjectivist ontology are also apparent, namely: nominalism and solipsism. In relation to the former, the contention is that things of a conceptual nature have a real existence (for example, ideas). As regards the latter, the assertion that consciousness 'is all that there is', is contrary to a materialist position where matter is believed to be the primary reality. Taking a different vein, some proponents of subjectivism advocate the view that knowledge is a social construction. It is not that there is 
a real world out there and we map our communication onto it; instead, according to certain post-structuralist philosophers, we create and reproduce this world through our continuing communication about it.

When it comes to axiology, subjectivism defends the value-laden nature of social inquiry. It is maintained that it is impossible to exclude the inquirer's values and the way they shape problem-definitions, choices, interpretations and decisions. The insurmountable divorce between the inquirer and what she or he studies, becomes untenable as everything succumbes to a perspectival gloss including science itself. To claim value-neutrality is to unintentionally endorse prevailing values inherent within the status-quo.

These ontological and epistemological premises shape modes of inquiry within subjectivism. Prominent here is phenomenology (the study of inner consciousness), hermeneutics (an inquiry into meaning), and social constructionism (the belief that social life is socially produced as opposed to naturally given). In addition, whereas objectivism is allied with a nomothetic stance (where the search for general patterns is to the fore), subjectivism leads to idiographic inquiry - focusing on cultural and historical particulars. In addition, it veers towards an inductive form of fact-finding, one where statements and ideas about the social world are drawn from a series of observations. Such meta-theoretical premises give rise to a distinctive approach to risk. Here, we see the use of structured judgement by professionals, attempts to extrapolate meaning from the various actors concerned in the risk situation, the application of heuristics of analysis (or short hand ways to making sense of complex scenarios) and reflexive accounts whereby risk assessors deliberate on 'facts and feelings' to gain a better understanding of predisposing and situational hazards. In a more developed version of this approach, risk assessors weigh up risk factors previously agreed consensually by experts. This has been referred to as a consensus model (Barber et al, 2008).

The objectivist and subjectivist paradigms can be counterpoised with the critical paradigm. The latter adopts the ontological position that social reality is both produced by humans but also exists in an objective sense. Bhaskar (1979) helpfully captures this notion in his metaphor of the scupltress (synonymous with the creative human agent) fashioning a material entity (representative of substantive social structure). Epistemologically, this paradigm argues that knowledge - of ourselves, others and the social world - can be used to highlight contradictions, distorted ideology, and oppressive discourse. Moreover, it can be used to develop ideal standards for appraising social life. Habermas (1986) expressed this well in his clarion call for an emancipatory science based on communicative rationality. For him, this embraced both positivism and hermeneutics but also moved beyond them to a new and different sphere of understanding of the social world where primacy was given to critical reflection and discourse.

In another vein, the critical paradigm unequoivocally asserts that, contra positivism, we can derive values from facts. Bhaskar and Habermas are two leading proponents of this 
contention. More specifically, they argue there is an unassailable linkage between epistemology and human emancipation. Taking things as they stand, it is better for people to hold true rather than false beliefs because of their respective outcomes for human actors. For them, it is possible, therefore, to provide 'an objective grounding to certain critical value judgements, and so to justify an emancipatory project of social change' (Benton and Craib, 2001, p. 137).

For Bhasker, this means identifying the underlying and often deep-rooted mechanisms that either work for human betterment and those, conversely, leading to deleterious outcomes. For instance, the fact that societies in the west have moved from a manufacturing to a consumptive-oriented mode of production has reinforced, wholesale, the mechanism of commodificaton. As a result, people become objects in the neo-liberal market. The task, here, for Bhaskar, is to not only identify these negative mechanisms but ameliorate them. This emancipatory principle applies to risk analysis where intrinsic mechanisms, affecting risk outcomes, operate within the person and also the wider, ecological environment. For example, a person's innate resilience might enable them to withstand the effects of a riskladen environment where poor human attachments exist. On a wider plane, access to social support and social capital might offset a potential negative chain reaction in a child's life. However, countervailing mechanisms may also be detected. On the psychological plane, children may develop insecure attachment profiles and live in socially impoverished environments ostensibly compromised by gender-related, racial and cultural inequalities.

It is important at this juncture to consider the strengths and weaknesses of each paradigm. Objectivism views risk as real and objective. It brings with it the fruits of the scientific method to provide an objective calculation of events. In doing so, it mitigates the bias inherent in contested fields such as child protection where cognitive blocks to recognition have been shown to intrude into decision-making (Munro, 1999). Moreover, it is accepted that some actuarial tools have a high predictive validity and credible inter-rater reliability (D'Andrade et al, 2005). Hence, they are likely to generate robust information for very busy, time-strapped professionals. That said, the continuing problem of the 'false positive' and 'false negative' continues to taint the overall value of such instruments particularly when they are applied to rare events such as serious child abuse. Consequently, they net a significant number of 'sharks' but also 'minnows'. More than this, actuarial tools do not in themselves take sufficient account of a child's social context nor how spatial and temporal arrangements change radiply to alter risk-profiles and trajectories. Social meaning and understanding is therefore a vital pre-requisite for using the actuarial tool. It can only be but one (important) resource in the professional's tool kitbag.

Subjectivism, with its emphasis on social meaning and context, helps to ameliorate these afore-mentioned difficiencies within the positivist approach to risk. Moreover, it seeks to understand (through phenomenology) and interpret (through hermeneutics) the actor's 
views of events. Crucially, if actors define a situation as real, it is real in its effects. What are presented as objective risks are subjectively perceived aspects of a person's life. Furthermore, real risk may be socially mediated by the social fields within which actors operate. As Douglas (1992) strikingly found, real risks are altered by cultural boundaries. So, subjectivism's emphasis on the meaning-making activies of the actor, including the risk situations they are embroiled in, must surely be its formative strength. Yet, as indicated above, our interpretations of events are notoriously compromised by bias or perhaps an ingrained habitus. We use heuristics to focus on information that is readily available or representative, discounting other possibilities. Or, we search for information that supports our pre-exisiting view and reject information which invalidates it. Inevitably, making sense of other people's sense-making activities - the double hermeneutic - is a fraught undertaking. Just as objectivism needs subjectivism to make it situationally sensitive, so subjectivism needs objectivism to provide it with detached rigour.

Moving on, the critical paradigm promulgates the unassailable fact that risk in human welfare is embued with oppression, inequality and asymmetrical power relations. This is one of its core contribution to the debate on risk. The connection between child abuse and poverty is irrefutable. As Munro (2007) cogently argues, social professionals are in danger of priviliging psychological explanations of child maltreatment, neglecting social aetiology. The critical paradigm also reinforces the vital idea that risk-related events in social life are caused by unseen mechanisms which we cannot observe empirically. This forces the assessor to construct and subsequently test hypotheses about them. In taking these much needed steps, the risk assessor is taking account of deep causality. This form of realist inquiry is known as retroduction. However, attempting to adopt it may not be as simple as it seems. Constructing and testing hypotheses about deep causal mechanisms is a complex process which may be more fitting for social researchers rather than busy practitioners in child protection. The challenges of applying the critical paradigm in practice are consequently to the fore.

If this meta-theoretical typology is accepted, where does all of this leave us? If we were to follow Thomas Kuhn (2012), we would answer the question by saying the three paradigms were incommensurable, presenting irreconcilable ontological, epistemological and methodological premises. Consequently, obeying the law on non-contradiction, the inquirer might be left with no option but to select (what he or she considered to be) the most enlightened paradigm to explain her lived reality, thereby rejecting the other two. From a purely logical point of view, Kuhn was right. However, when it comes to risk in child welfare, there might be strong arguments in favour of avoiding ontological closure and separatism within meta-theory (even if merited by abstract logic) and encouraging a more pragmatist stance, one adhering to paradigmatic pliability. Put more simply, there might be much to gain from aligning all three paradigms (even though this might induce uncomfortable tensions) when it comes to the issue of risk in child welfare. This is to side-step the 
internecine risk wars referred to earlier and encourage an exchange of ideas across what might be re-framed as more porous boundaries between the paradigms. More moderate expressions might facilitate points of alignment, or convergence. Put in another way, reallife investigators are unlikely to adopt a strong, purist or traditional version of any particular paradigm. Perspectives are more likely to be two-eyed. Let us consider, for example, the tenets of a moderate form of objectivism in social inquiry. Here, objectivism is tempered with subjectivist notions. Layder (1997) is an advocate of this re-worked position. For him, 'the objective realm of social phenomena must be recognised and properly analysed' ( $p$. 10). Yet, in arguing this point, he maintains that the viewpoint of the actor is of critical importance. This is because actors socially construct their realities even though the objective world exits outside of them. Society is viewed as the outcome of human perception and activity but constrains and enables that activity by imposing rules, rituals and norms on it. Here, we can see how objectivism and subjectivism have been aligned pragmatically.

There are other philosophical and sociological precedents for this pragmatist stance. Isaiah Berlin (2003), for instance, extolled the view that seemingly competing, incommensurate perspectives could be reconciled in a creative, pluralistic fusion without succumbing to a relativist abyss. Echoing this stance, Nicos Mouzelis called for a conceptual pragmatism between paradigms of thought in the social sciences based on the 'criteria of utility rather than truth (1995, p. 7). In a comparative vein, George Ritzer (1980) argued for paradigm linking, leaping, bridiging and integrating. Lastly, the philosopher and theologian Paul Tillich (1966) surmised that the 'boundary' between dichotomous perspectives was often the most creative of places to rest, in terms of knowledge acquisition.

Deliberating on the boundaries between objectivist, subjectivist and critical paradigms of risk, and thereby harnessing important insights from each in a synergistic way, leads me to develop a resultant, derivative position I have dubbed 'methodological pragmatism'. This not simply an amalgam of different premises from each paradigm; rather, it is a gestalt - a conceptualisation that is more than the 'sum of the parts'. Methodological pragmatism takes on its own particular hue even though it is indebted to core ideas within the three paradigms outlined earlier. Critically, however, I have not constructed it as a fourth paradigm as it does not possess the internal consistency required of this meta-theoretical construct (Kuhn, 2012). As a derivative position, I contend methodological pragmatism makes a number of salient propositions about the social world and risk. These are set out below. 


\section{Core Propositions Underpinning Methodological Pragmatism and Risk}

(i) Approaches to risk should hold objectivist and subjectivist perspectives together in a creative tension. This results in method triangulation whereby social workers use the most sensitive, specific, actuarial models (derived from the objectivist paradigm) but also attend to the contextual and situational factors affecting actors' meanings (which are part and parcel of a subjectivist orientation). How the service user views his or her life, signifcant others, key events and so on, places actuarial findings in an important context ostensibly qualifying initial formulations on risk in a more nuanced and situation-specific manner. Not only that, a focus on objective risk factors, without attending to the social context within which they are imbedded, can potentially skew or distort their real significance. For example, a social worker needs to understand how a step-parent (a risk factor in many riskassessment schedules) is perceived by the child in whose care she resides. It might be that the child is deeply attached to her step-father. It could be that the step-father sees himself as the child's psychological parent - genetic differences being put to one side. These emotional affiliations mollify any potential concerns arising from the presence of a step-father in the home. Similarly, a parent who has committed a criminal offence (say tax fraud) is unlikely to pose any risk to a child. It is the nature of the offence, its meaning and context, that is all important. Informed risk assessments in social work must attend to meaning, time and place.

(ii) Importantly, risk assessors will necessarily adopt various types of hermeneutic analysis. First, they should adopt an insider perspective, seeing the world from the service user's point of view, particularly as regards the risk factors in their lives. Then again, secondly, it means looking at these meanings from a different angle, asking questions and puzzling over different interpretations. This process can be described as moving from a hermeneutic of empathy to a hermeneutic of questioning. Lastly, and more than that, it involves social workers engaging in the double-hermeneutic when approaching situations of risk. That is, they are trying to make sense of service users attempting to make sense of their experience. Accordingly, social workers' sense-making activity is of a second-order kind. Moreover, as this is a complex task, it is best undertaken in the context of supportive, reflective supervision. It is also a matter of intelligent, accurate, empathetic perspective-taking with service users. This commitment humanises risk assessment in social work, placing the person at the centre of inquiry. Service users cannot be reduced to an objective list of risk factors. A hermeneutic of empathy builds from an ethic of care recognising how service users might struggle with internal and external stressors and surrounding hazards. Hence, risk assessment in social work is a person-centred process not just a technical activity. 
(iii) Risk assessors, in line with the critical paradigm, should investigate the deep causal mechanisms leading to harm and well-being and, importantly, locate oppressive mechanisms lying below the surface of everyday experience. This involves a process of identifying causal mechanisms within the person (such as personality traits) and various domains of social life (for example, rules governing social interaction). Once these mechanisms have been identified, social workers must seek to mitigate those causing harm (for example, insecure attachment and stigma in children and young people) and strengthen those leading to positive effects (for instance, resilience, social support, and emotional literacy).

(iv) What makes methodological pragmatism unique (as a position) is the manner in which 'facts and feelings' emanating from the application of (i), (ii) and (iii) are processed holistically. This is a matter of sifting through hypotheses developed from positivist, hermeneutic and critical conceptions and integrating them where possible to provide multi-faceted explanations. This is best done communicatively with others to make linkages, form hypotheses and, crucially, enact reflexivity. It is like seeing life through each side of a prism and moving to a centre-point in the middle where a leap in understanding occurs. For social workers, such insight informs practice knowledge which, for Trevithick (2009), 'describes how knowledge can be used in different practice situations to produce sound judgements and effective decision-making' (p. 43).

(v) Risk assessment in child welfare is both fact and value-laden. For example, a parent who fails to turn up for a contact visit with his child is an event that is indisputably the case. Yet, it can be viewed subjectively and has ethical connotations, particularly if the event has caused some kind of harm. Every pronouncement on risk therefore has a moral dimension. Social workers need to be trained as technicists, therefore, in the science of risk appraisal but also need to understand how to process complex, ethical quandaries. It is here that an understanding of moral philosophy becomes both helpful and required.

In all of this, social workers apply practical reasoning to make sense of the facts and feelings emerging from risk assessment. According to the philosopher Alisdair Maclntyre (1999), practical reasoning occurs when a person thinks critically about his or her natural attitude (which was referred to earlier): her views, perceptions and judgements and shares them with others as part of a collaborative discussion. Moreover, practical reasoning is a matter of reflecting on whether the basis of one's thoughts and actions are credible and supported by justifiable, ethical reasons. To reiterate, this is not only a cognitive activity but a moral and collective one aimed at building virtue in social workers particularly when it is habituated. For Pullen-Sansfacon (2010), practical reasoning is the key 
pedagogical medium through which social workers build and sustain virtue in their practice. She proposes that social work students are encouraged to apply Socratic dialogue as one pedagogical strategy for developing practical reasoning.

(vi) From an ontological standpoint, the social actor is a complex social being, and, as a consequence of past psycho-biographical experience, might well show ambivalence or resort to defence mechanisms to protect a vulnerable identity. This is especially true in cases where unmet emotional needs are to the fore. While phenomenological approaches to risk are necessary, they cling to an overly rational view of the actor, neglecting these areas. Risk assessment in child welfare must therefore take into account emotion, human attachment, object-relations and the unconscious - but not in an overly deterministic way. In child protection, powerful psycho-dynamic processes - transference, projective identification, and splitting - operate particularly when professional authority has to be exercised. In this context, Reder et al (1999) have argued convincingly that unmet care and control needs feature strongly in the psycho-biographies of parents and caregivers who seriously harm their children. For these authors, social workers must be attentive to psycho-dynamic processes particularly in the context of how they balance care and control responses when faced with risk-laden situations. Rustin (2005) concurs with this recommendation adding that social workers need to be mindful of how they unconsciously avoid pain in child protection. For her, mindfulness is the antidote to mindless practice.

(vii) Social life exhibits a number of collective properties that historically emerge to form objective features which provide a wider context for understanding risk. For example, families often follow established, pre-existing rules, routines and norms outlining the possibilities and constraints of social interaction. Risk assessors must become acquainted with these taken-for-granted, objective aspects of family life if they are to put behaviours within a meaningful context. Parenting assessments in social work must focus on these rules and norms. For example, how are roles within the family allocated? How is communication structured? In what way is decision-making enacted? There may be rules relating to the behavioural management of children which are important for social work assessors to understand. Families use distinctive methods of making sense of their worlds. When social workers gain insight into these methods they are adhering to ethnomethodology - a primary method of investigation within the subjectivist paradigm (de Montigny, 2007).

(viii) Oppressive, social mechanisms affecting risk do not operate independently of people but have properties that are not reducible to them. For instance, poverty exists as a real, objective dimension sui generis. While people live with and 
experience poverty, we cannot explain it solely in terms of their perceptions or reactions. Moreover, parents of children 'in need' should not be blamed for their pecuniary status. Poverty has its own defining mechanisms (such as the barriers it presents to various forms of capital) which need to be understood in a comprehensive risk assessment. Another way of putting this is to say that human activities involving risk are the outcome of the dual influence of external (macro) factors and situational (micro) factors. In this interplay inequality affects life outcomes and heightens risk profiles and careers.

(ix) Risk should be seen in the context of the influence of different domains of social life: self, social interaction, institution, culture and economy. These domains are distinct yet connected. Another way of putting this is to say that risk outomes are affected by the interplay between human agency and social structure. This imbrication takes place within time and space. The level and seriousness of risk in child welfare may consequently change when actors move to different settings or through the simple passage of time. To reiterate, risk should be seen in the context of agency, structure, time and place.

(x) Power operates pervasively in social life to effect and reinforce asymmetries in social relationships and positions based on gender, racial, cultural and class-based differences. Power is variegated and often disciplinary placing subjects under surveillance and control. Risk assessors in child welfare must be aware of their own power, its potential for pacifying, excluding and normalising less powerful groupings subject to the professional 'gaze'. Power, though, also has an enabling dimension and it is here that risk practices should be seen as empowering growth and purposeful change.

The afore-mentioned propositions cohere around a number of recurring and salient features of methodological pragmatism that have a direct bearing on risk assessment in child welfare. It is worth rehearsing them. First, given the ontological significance of the different domains of life, it is vital that risk assessment keeps to an ecological focus. That is, it is necessary to understand the person-in-society nexus. Risk factors exist with the person and also within wider social, cultural and economic mileux. Second, risk assessment must move from being a surface appraisal (of facts and feelings) to one of depth. It is important here that risk assessors are attuned to 'deep causality' for the social world is not a flat, featureless terrain. Unless this insight is apprehended, change might be difficult to achieve. To reiterate: risk assessment must have epistemological depth for this allows the inquirer to understand not only what the actor is doing but also how and why she is doing it.

Third, risk assessment must avail of triangulation using different types of tool coterminously - some more objectively oriented, others attuned to subjective approaches such as structured observation. It is only through triangulation we can hope to enhance the 
validity and reliability of assessment. Fourth, this position highlights the ethical nature of risk assessment and intervention and, primarily, that it should lead to human emancipation and well-being. This is congruent with anti-oppressive social work practice. Risk calculation is not an end in itself; instead it ought to be a means to a humanistic end. Fifth, methodological pragmatism is deeply concerned with the meaning service users attribute to their experience. It values a perspectival stance and, with it, the importance of professional reflexivity - given that social workers are also meaning-oriented actors. However, reflexivity raises the need for considered supervision and support. Hence, the supervisor must be open to the tenets of methodological pragmatism as much as the practitioner. Lastly, there is an archeological theme underpinning this position. This suggests that advanced social work practice must not only strive to apprehend and apply relevant substantive theory (to explain events in the empirical world) but also to delve deeper into the meta-theoretical substratum underpinning each and every aspect of the lifecourse. This return to meta-theoretical preliminaries engenders a consideration of the interconnection between knowledge, 'being' and wider moral arguments about risk in child welfare.

\section{Conclusion}

In this paper I have described some of the first-order, meta-theoretical premises underpinning risk assessment in child welfare to contribute to a growing debate about the nature of risk in child welfare. Three governing paradigms were identifed and their component parts explained. This critical review subsequently led to the development of a composite position and, with it, a number of propositions about the fundamental nature of risk assessment. This project has been about defending philosophy in a run away world that priviliges instrumentalism in social life, reinforces social relations and devalues deep critical inquiry. It is about valuing and respecting the complexity of philosphical investigation. By returning to this level of deep understanding and integration we can enhance our knowledge of the person-in-society and the risks he or she faces and presents. It is to acknowledge there is a real world out there but one that we dimly perceive much like the incumbents in Plato's cave. Advancing our understanding of meta-theory casts further light on the walls of this enclosure so we can grasp the nature of reality with even greater confidence. I contend meta-theoretical awareness should become an integral part of social work education so that students become increasingly open to this deep level of understanding - and comfortable using the vernacular that explains it. Social work education must revel in subtleties, contradictions and lacunae enabling students to become more adept explorers of the social world in all its dimensions. 


\section{References}

Barber, J., Shlonsky, A., Black, T. \& Trocome, N. (2008). Reliability and Predictive Validity of a Consensus-based Risk Assessment Tool. Journal of Public Child Welfare, 2(2), 173-195.

Barsky, A. (2009). The Legal and Ethical Context for Knowing and Using the Latest Child Welfare Research. Child Welfare, 88(2), 69-92.

Beck, U. (1992). Risk Society: Towards a New Modernity. London: Sage.

Benton, T. \& Craib, I. (2001). Philosophy of Social Science: The Philosophical Foundations of Social Thought. Basingstoke: Palgrave.

Berlin, I. (2003). The Crooked Timber of Humanity. London: Pimlico.

Bhaskar, R. (1979). The Possibility of Naturalism. Brighton: Harvester.

Broadhurst, K., Hall, C., Wastell, D., White, S. \& Pithouse, A. (2010). Risk, Instrumentalism and the Human Project in Social Work: Identifying the Informal Logics of Risk Management in Children's Statutory Services. British Journal of Social Work, 40(4), 1046-1064.

Burrell, G. \& Morgan, G. (1979). Sociological Paradigms and Organizational Analysis. London: Heinemann.

Chua, W.F. (1986). Radical Developments in Accounting Thought. The Accounting Review, 61(4), 601-32.

D’Andrade, A., Benton, A. \& Austin, M. (2005). Risk and Safety Assessment in Child Welfare: Instrument Comparison. Berkeley: Bay Area Social Services Consortium.

Dahrendorf, R. (1959). Class and Class Conflict in Industrial Society. London: Routledge.

De Montigny, G. (2007). Ethnomethodology for Social Work, Qualitative Social Work, 6, 95120.

Douglas, M. (1992). Risk and Blame: Essays in Cultural Theory. London: Routledge.

Giddens, A. (1987). Social Theory and Modern Sociology. Stanford: Stanford University Press. Habermas, J. (1986). Knowledge and Human Interests. Cambridge: Polity.

Hunt, S. (2005). The Life Course: A Sociological Introduction. London: Palgrave Macmillan. Kemshall, H. (2009). Risk Rationalities in Contemporary Social Work Policy. British Journal of Social Work, 40(4), 1247-1262. 
Kuhn, T. (2012). The Structure of Scientific Revolutions ( $4^{\text {th }}$ ed.). Chicago: University of Chicago Press.

Lawler, S. (2008). Identity: Sociological Perspectives. Cambridge: Polity Press.

Layder. D. (1997). Modern Social Theory: Key Debates and New Directions. London: UCL Press.

Lonne, B., Parton, N., Thomson, J. \& Harries, M. (2009). Reforming Child Protection. New York, Routledge.

Mouzelis, N. (1995). Sociological Theory: What Went Wrong? Diagnoses and Remedies. London: Routledge.

Munro, E. (1999). Common Errors of Reasoning in Child Protection Work. Child Abuse and Neglect, 23(8), 745-758.

Munro, E. (2007). Child Protection. London: Sage.

Mclntyre, A. (1999). Dependent Rational Animals - Why Human Beings Need the Virtues. London: Duckworth.

Parsons, T. (1937). The Structure of Social Action. New York: McGraw-Hill.

Popper, K. (1968). The Logic of Scientific Discovery. London: Hutchinson.

Pullen-Sansfacon, A. (2010). Virtue Ethics for Social Work: A New Pedagaogy for Practical Reasoning. Social Work Education: The International Journal, 29, 402-415.

Reder, P., Duncan, S. \& Gray, M. (1999.) Beyond Blame: Child Abuse Tragedies Revisted. London: Routledge.

Ritzer, G. (1980). Sociology: A Mulitiple Paradigm Science. Boston: Allyn and Bacon.

Rustin, M. (2005) Conceptual Analysis of Critical Moments in Victoria Climbie's Life. Child and Family Social Work, 10, 11-19.

Schwalbe, C. (2004). Re-visioning Risk Assessment for Human Service Decision-making. Children and Youth Services Review, 26(6), 561-576.

Shlonsky, A. \& Wagner, D. (2005). The Next Step: Integrating Actuarial Risk Assessment and Clinical Judgement into an Evidence-Based Practice Framework in CPS Case Management. Children \& Youth Services Review, 27(4), 409-427.

Sibeon, R. (2004). Rethinking Social Theory. London: Sage.

Tillich, P. (1966). On the Boundary. New York: Scribner's. 
Trevithick, P. (2009). Social Work Skills: A Practice Handbook. Berkshire: Open University Press.

White, A. \& Walsh, P. (2006). Risk Assessment in Child Welfare: An Issues Paper. NSW, Centre for Parenting \& Research. 